\title{
Ultra-high-speed optical signal processing of serial data signals
}

Clausen, Anders; Mulvad, Hans Christian Hansen; Palushani, Evarist; Galili, Michael; Hu, Hao; Ji, Hua; Xu, Jing; Laguardia Areal, Janaina; Jeppesen, Palle; Oxenløwe, Leif Katsuo

\section{Published in:}

Proceedings of International Conference on Transparent Optical Networks (ICTON)

Link to article, DOI:

10.1109/ICTON.2012.6254491

Publication date:

2012

Link back to DTU Orbit

Citation (APA):

Clausen, A., Mulvad, H. C. H., Palushani, E., Galili, M., Hu, H., Ji, H., Xu, J., Laguardia Areal, J., Jeppesen, P., \& Oxenløwe, L. K. (2012). Ultra-high-speed optical signal processing of serial data signals. In Proceedings of International Conference on Transparent Optical Networks (ICTON) (pp. Tu.A4.4). IEEE. https://doi.org/10.1109/ICTON.2012.6254491

\section{General rights}

Copyright and moral rights for the publications made accessible in the public portal are retained by the authors and/or other copyright owners and it is a condition of accessing publications that users recognise and abide by the legal requirements associated with these rights.

- Users may download and print one copy of any publication from the public portal for the purpose of private study or research.

- You may not further distribute the material or use it for any profit-making activity or commercial gain

- You may freely distribute the URL identifying the publication in the public portal 


\title{
Ultra-high-speed optical signal processing of serial data signals
}

\author{
A. T. Clausen, H. C. Hansen Mulvad, E. Palushani, M. Galili, H. Hu, H. Ji, J. Xu, J. Laguardia Areal, \\ P. Jeppesen, L. K. Oxenløwe \\ Department of Photonics Engineering \\ Technical University of Denmark, Ørsteds Plads 34, DK-2800 Kongens Lyngby, Denmark \\ Tel: (+45) 4525 3779, Fax: (+45) 4593 6581, e-mail: ancl@fotonik.dtu.dk
}

\begin{abstract}
To ensure that ultra high-speed serial data signals can be utilised in future optical communication networks, it is indispensable to have all-optical signal processing elements at our disposal. In this paper, the most recent advances in our use of non-linear materials incorporated in different function blocks for high-speed signal processing are reviewed.
\end{abstract}

Keywords: OTDM, Optical Fourier Transformation, signal processing, serial-to-parallel conversion.

\section{INTRODUCTION}

Internet traffic is constantly growing [1-2] and predictions of the future traffic expect this trend to continue [2-3]. The capacity has persistently been upgraded to support this increase exemplified by the release of the IEEE standardisation of 40 and $100 \mathrm{Gbit} / \mathrm{s}$ communication in 2010 [4]. Despite these initiatives, predictions indicate that the apparently unlimited fibre capacity will be insufficient long before 2025 [3]. Consequently, an ongoing quest for more capacity, lower power consumption and reduced physical footprints spur researchers on worldwide to explore the feasibility of a wide variety of potential candidates to achieve these objectives. Impressive experiments demonstrating both generation and detection of signals with colossal aggregated bit rates can be found in the literature. For the purpose of this paper, the experiments can be divided into multi-carrier and single carrier experiments.

In the multi-carrier experiments a number of Wavelength Division Multiplexing channels and/or Orthogonal Frequency Division Multiplexing (OFDM) channels are modulated often utilising both advanced modulation formats such as higher order Quadrature Amplitude Modulation (QAM) formats or Quadrature Phase Shift Keying (QPSK) combined with Polarisation Division Multiplexing (PDM) showing bit rates, after subtracting the assumed Forward Error Correction (FEC) overhead of $20 \mathrm{Tbit} / \mathrm{s}$ [5], $101 \mathrm{Tbit} / \mathrm{s}$ [6] and $102 \mathrm{Tbit} / \mathrm{s}$ [7]. If using several cores in the fibre, Space Division Multiplexing (SDM) can be used to increase the bit rate even further. By using 3 and 19 fibre cores, bit rates of 109 Tbit/s [8] and very impressive 305 Tbit/s [9] have been demonstrated. Despite using different schemes to achieve these results, they all have one thing in common; the symbol rate is defined and limited by the driving electronics, thus the symbol rate of [5-9] is varying between 5.5 to 43 GBaud.

In parallel with the work on utilising a huge number of carriers, a similar increase in the bit rate on a single carrier has been demonstrated. By using the Time Division Multiplexing scheme in the Optical domain, i.e. OTDM, the serial symbol rate is far beyond the maximal electric bandwidth. Already back in 1998 a ground breaking experiment demonstrated a symbol rate of $640 \mathrm{Gbit} / \mathrm{s}$ [10], which was not surpassed before 2009 where the symbol rate was doubled to $1.28 \mathrm{Tbit} / \mathrm{s}$ [11]. However, just as seen in the multi-carrier demonstrations, the bit rate can be increased further by utilising QAM, QPSK and PDM and $5.1 \mathrm{Tbit} / \mathrm{s}$ [12] and $9.5 \mathrm{Tbit} / \mathrm{s}$ [13] are recent reported results.

In this paper, a short introduction to the required functional blocks required to implement an ultra-high-speed serial OTDM system is given. A number of different materials have shown its worth by providing sufficient efficiency to demonstrate several functionalities and a short resume of the most noticeable results is given. Finally a brief introduction to serial-to-parallel conversion between OTDM and WDM is provided, followed by some of the most recent results using this scheme.

\section{The basic OTDM system}

In Fig. 1 the basic principle of an on-off keying OTDM system is shown and it constitutes the bread and butter of all the ultra-high-speed experiments referred to in e.g. [10-13]. 


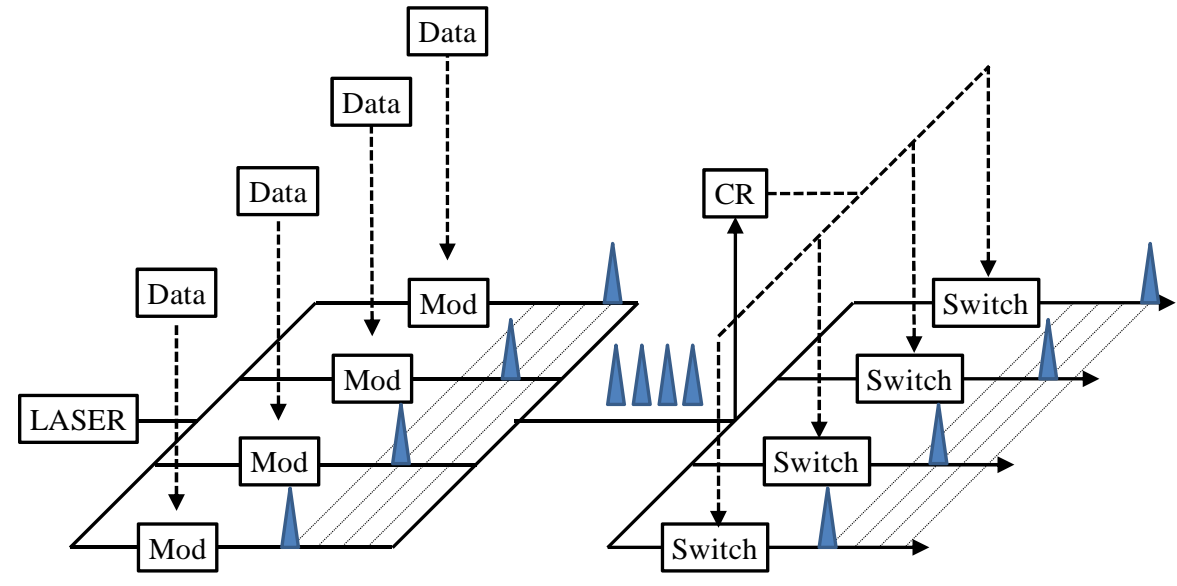

Figure 1. Principle of an Optical Time Division Multiplexed point-to-point system

The pulse source is the main component of the transmitter. It generates a pulse train of Return-to-Zero (RZ) pulses characterised by e.g. shape, temporal Full Width Half Maximum (FWHM) width, timing jitter and repetition rate $\mathrm{B}$, labelled the base rate frequency. The pulse train is split into $\mathrm{N}$ branches, each including an external modulator which intensity modulates the pulse trains with unique data streams. If the pulses are sufficiently narrow, a specifically designed time delay in each branch, allows the $\mathrm{N}$ data signals to be bit interleaved, i.e. multiplexed, thus generating an aggregated OTDM data signal with a bit rate of NB bit/s. When detecting the signal, the ultra-fast OTDM data signal should be downscaled in bit rate, allowing electronics to process the signal. In the transmitter, it was relatively easy to overcome the potential bit rate limitations induced by the low bandwidth of the electronics. However, in the receiver, the OTDM scheme takes its toll, as detection of the signal is very challenging; both clock recovery and demultiplexing of each tributary channel are required. A part of the OTDM signal is tapped for the Clock Recovery (CR) circuit, which extracts a clock corresponding to the base rate frequency B of the OTDM signal. Because the OTDM signal does not include a distinct frequency component at $\mathrm{B}$, the clock extraction is challenging and modifications of existing clock recovery schemes are required. The base rate clock is applied as a control signal to the switches, used to optically demultiplex each individual time channel from the aggregated data signal. Until recently, no existing switches offered demultiplexing of all channels using only one single switch and consequently an array of switches were envisioned, as sketched in Fig 1. Each of the demultiplexed base rate signals can subsequently be detected, by injecting the signals into base rate receivers triggered by the base rate clock. Hence, by using relatively slow electronics, very high-speed optical signals can be generated and detected. By adding extra complexity to the setup in terms of multilevel modulation formats hereby imposing extra data to each symbol and combining this with polarisation multiplexing, the total bit rate on a single carrier can be increased substantially.

A number of different materials with sufficiently high non-linearity have been successfully utilised to implement some of the key signal processing functionalities shown in Fig. 1. Some of the most noticeable results are demultiplexing from $1.28 \mathrm{Tbit} / \mathrm{s}$ to base rate using Highly Nonlinear Fibre (HNLF) [11], Chalcogenide (ChG) planar waveguides [14] and nano-engineered Silicon waveguides [15], whereas Semiconductor Optical Amplifier (SOA) based switches have been used for $640 \mathrm{Gbit} / \mathrm{s}$ demultiplexing [16]. Clock Recovery extracting the pre-scaled clock at base rate from $640 \mathrm{Gbit} / \mathrm{s}$ have been demonstrated using SOA [16] and Periodically Poled Lithium Niobate (PPLN) [17] devices.

In Fig. 1, it is tacitly assumed that it is possible to connect the high-speed transmitter and receiver via a fibre transmission span. However, due to the narrow pulses of the transmitter, the spectrum is very broad and is consequently quite sensitive to even small values of uncompensated dispersion. Nevertheless, high-speed transmission has been demonstrated both in laboratory environment see e.g. [13] and in deployed fibres [18].

\section{Serial to Parallel conversion of OTDM to WDM signals}

The receiver depicted in Fig. 1 based on an array of switches may not be efficient in terms of footprint and power consumption. With the advent of the time lens concept and time-domain Optical Fourier Transformation (OFT) technique [19-20] a number of interesting functional blocks can be implemented including a scheme for mapping the tributary time channels in the OTDM signal into parallel WDM channels thus essentially performing the required demultiplexing of the OTDM signal [21-22]. The principle of the OFT scheme is based 
on the interplay between linear chirp and quadratic phase modulation of the incoming signal. Linear chirp can be applied to the incoming signal by transmission through a dispersive element such as a fibre, whereas quadratic phase modulation can be imposed on the signal by using a parametric process such as Four Wave Mixing (FWM) [23]. The principle is shown in Fig. 2 where an incoming OTDM signal is dispersed and combined with a chirped pump signal before being injected into a FWM device. At the output of the device, the FWM-generated idler signal will include the mapped OTDM channels if chirp and phase modulation are balanced correctly, see e.g. [24]. Each individual demultiplexed channel can be extracted using e.g. a passive filter like an Arrayed Waveguide Grating (AWG) as indicated in Fig. 2.
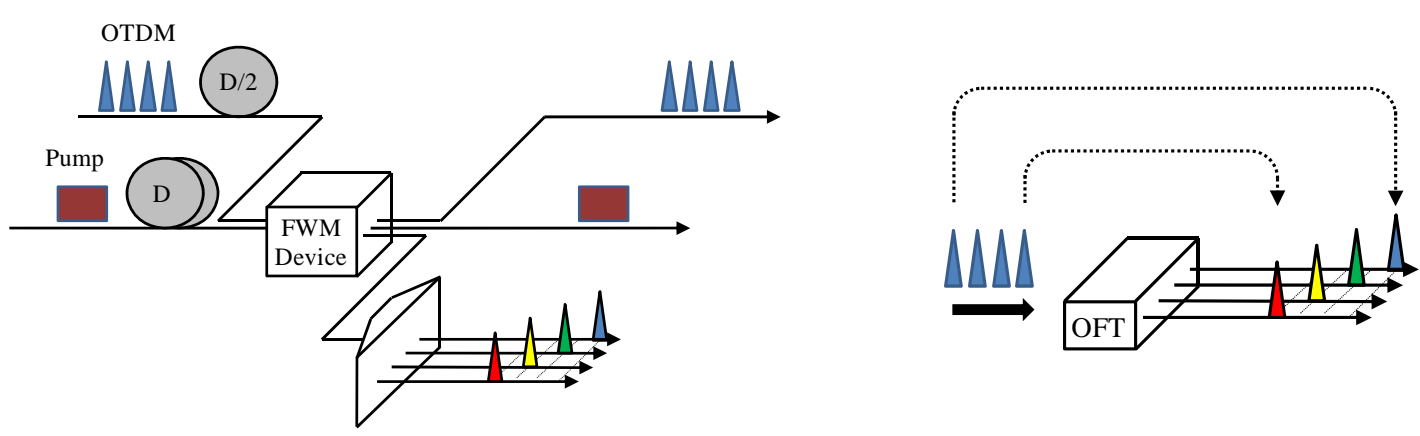

Figure 2. Left: Principle of OFT for serial to parallel conversion used to map each individual OTDM channels to separate wavelength. Right: conceptual illustration of mapping between OTDM temporal channels and WDM wavelengths .

An example of this powerful scheme is reported in [21-22]. An incoming $640 \mathrm{Gbit} / \mathrm{s}$ OTDM-DPSK signal is linearly chirped and injected into a silicon nanowire together with a $\sim 80$ ps square temporal linear chirped pump pulse at the base rate of $10 \mathrm{GHz}$. At the output of the silicon device, $25 \mathrm{GHz}$ spaced DWDM channels are generated, and can be accessed individually using a tuneable filter. In Fig. 3 (left) the output spectrum of the silicon device is shown. Additionally the DWDM spectrum and the corresponding BER performance of each channel are shown to the right. With this set-up 40 channels out of a total of 64 channels could be converted error-free, i.e. below the FEC limit. In principle this would suggest that only 2 FWM devices would be needed to demultiplex all the channels. If the structure depicted in Fig. 1 is used, 64 parallel switches would be needed to demultiplex all the channels simultaneously. Thus, this scheme offers a substantial reduction in complexity of the OTDM receiver. Furthermore, it is speculated whether this indeed could be more energy efficient [25].
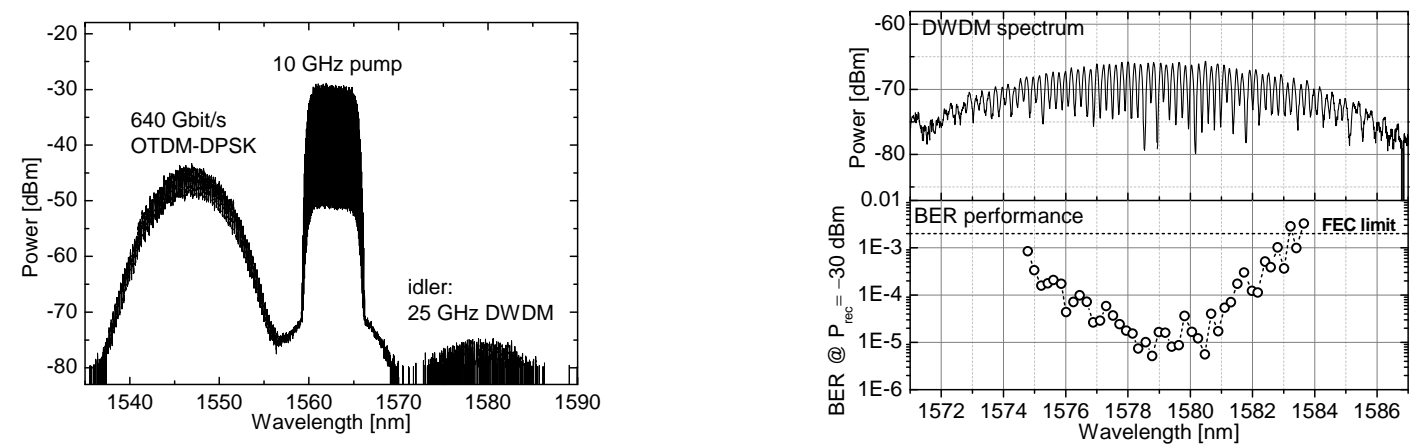

Figure 3. To the left the output spectrum of the silicon devise is shown. To the right a more detailed spectrum of the converted OTDM channels with the corresponding BER values.

\section{CONCLUSION}

In this paper it was described how OTDM systems rely heavily on components with sufficiently high nonlinearity enabling processing of the signal at bit rates which outperform their electrical counterparts. Many different materials can be used for signal processing and highlights from literature have been summarised. Finally, a recent scheme based on time-domain Optical Fourier Transformation technique has been emphasised as it may reduce the complexity of an OTDM system and potentially decrease the power consumption of the system.

\section{REFERENCES}

[1] DE-CIX: Traffic Statistics, http://www.de-cix.net/about/statistics/ (2012)

[2] M. Mauldin: The State of the Global Internet, Webinare, “www.telegeography.com (2011). 
[3] E. B. Desurvire: Capacity Demand and Technology Challenges for Lightwave Systems in the Next Two Decades, Journal of Lightwave Technology, Vol. 24, No. 12, pp. 4697-4710, 2006.

[4] IEEE Std 802.3ba-2010: Amendment 4: Media Access control parameters, physical layers and management parameters for $40 \mathrm{~Gb} / \mathrm{s}$ and $100 \mathrm{~Gb} / \mathrm{s}$ operation.

[5] D. Hillerkuss, et al.: 26 Tbit/s line-rate super-channel transmission utilizing all-optical fast Fourier transform processing, Nature Photonics, DOI:10.1038/NPHOTON.2011.74, 2011.

[6] D. Qian, , et al.: 101.7-Tb/s (370x294-Gb/s) PDM-128QAM-OFDM Transmission over 3x55 km SSMF using Pilot-based Phase Noise Mitigation, Proc. OFC 2011, Los Angeles, California, USA, 2011, paper PDPB5.

[7] A. Sano, et al.: 102.3-Tb/s (224x548-Gb/s) C- and Extended L-band All-Raman Transmission over 240 km Using PDM-64QAM Single Carrier FDM with Digital Pilot Tone, Proc. OFC 2012, Los Angeles, California, USA, 2012, paper PDP5C.3.

[8] J. Sakaguchi, et al.: 109-Tb/s (7x97x172-Gb/s SDM/WDM/PDM) QPSK transmission through 16.8-km homogeneous multi-core fiber, Proc. OFC 2011, Los Angeles, California, USA, 2011, paper PDPB6.

[9] J. Sakaguchi, et al.: 19-core fiber transmission of 19x100x172-Gb/s SDM-WDM-PDM-QPSK signals at 305Tb/s, Proc. OFC 2012, Los Angeles, California, USA, 2012, paper PDP5C.1.

[10] M. Nakazawa, et al.: TDM single channel 640 Gbit/s transmission experiment over $60 \mathrm{~km}$ using $400 \mathrm{fs}$ pulse train and walk-off free, dispersion flattened nonlinear optical loop mirror, Electronics Letters, Vol. 34, No. 9, pp.907-908, 1998.

[11] H. C. Hansen Mulvad, et al.: 1.28 Tbit/s single-polarisation serial OOK optical data generation and demultiplexing, Electronics Letters,Vol. 45, No. 5, pp. 280-281, 2009.

[12] H. C. Hansen Mulvad, et al.: Demonstration of 5.1 Tbit/s data capacity on a single-wavelength channel, Optics Express,Vol. 18, No. 2, pp. 1438-1443, 2010.

[13] T. Richter, et al.: Single Wavelength Channel 10.2 Tb/s TDM-Data Capacity using 16-QAM and Coherent Detection, Proc. OFC 2011, Los Angeles, California, USA, 2011, paper PDPA9.

[14] T. D. Vo, et al.: Photonic chip based transmitter optimization and receiver demultiplexing of a $1.28 \mathrm{Tbit} / \mathrm{s}$ OTDM signal, Optics Express,Vol. 18, No. 16, pp. 17252-17261, 2010.

[15] H. Ji, et al.: Optical Waveform Sampling and Error-Free Demultiplexing of $1.28 \mathrm{~Tb} / \mathrm{s}$ Serial Data in a Nanoengineered Silicon Waveguide, Journal of Lightwave Technology,Vol. 29, No. 4, pp. 426-431, 2011.

[16] E. Tangdiongga, et al.: SOA-based Clock Recovery and Demultiplexing in a Lab Trial of 640 Gb/s OTDM transmission over 50-km Fibre Link, Proc. ECOC 2007, Berlin, Germany, 2007, paper PD1.2.

[17] L. K. Oxenløwe, et al.: 640 Gbit/s clock recovery using periodically poled lithium niobate, Electronics Letters, Vol. 44, No. 5, pp. 370-372, 2008.

[18] $\mathrm{H}$. Hu, et al.: 640 Gbaud NRZ-OOK data signal generation and 1.19 Tbit/s PDM-NRZ-OOK field trial transmission Proc. OFC 2012, Los Angeles, California, USA, 2012, paper PDP5C.7.

[19] B. H. Kolner: Space-Time Duality and the Theory of Temporal Imaging, Journal of Quantum Electronics, Vol. 30, No. 8, pp. 1951-1963, 1994.

[20] T. Hirooka, et al.: Optical Adaptive Equalization of High-Speed Signals Using Time-Domain Optical Fourier Transformation, Journal of Lightwave Technology,Vol. 24, No. 7, pp. 2530-2540, 2006.

[21] H. C. Hansen Mulvad, et al.: Ultra-High-Speed Optical Serial-to-Parallel Data Conversion in a Silicon Nanowire, Proc. ECOC 2011, Geneva, Switzerland, 2011, paper Th.13.A.2.

[22] H. C. Hansen Mulvad, et al.: Ultra-high-speed optical serial-to-parallel data conversion by time-domain optical Fourier transformation in a silicon nanowire, Optics Express, Vol. 19, No. 26, pp. 825-835, 2011.

[23] C. V. Bennett, et al.: Principles of Parametric Temporal Imaging -Part I: System Configurations, Journal of Quantum Electronics, Vol. 36, No. 4, pp. 430-437, 2000.

[24] E. Palushani, et al.: OTDM-to-WDM Conversion Based on Time-to-Frequency Mapping by Time-Domain Optical Fourier Transformation, Journal of Selected Topics in Quantum Electronics, Vol. 18, No. 2, pp. 681-688, 2012.

[25] L. K. Oxenløwe et al.: Ultrafast Nonlinear Signal Processing in Silicon Waveguides”, Proc. OFC 2012, Los Angeles, California, USA, 2012, paper OTh3H.5 (invited paper). 